\title{
COVID-19 Pandemic Practices, Payment Models, and Publication Successes: Family Medicine Studies a Variety of Primary Care Questions
}

\author{
Marjorie A. Bowman, MD, MPA, Dean A. Seebusen, MD, MPH, and \\ Christy J. W. Ledford, PhD
}

This issue provides inspiring reports of family medicine during the Coronavirus disease 2019 (COVID-19) pandemic and the provision of just-in-time COVID-19 information for clinicians. Conversely, burnout - yes or no? The issue includes information that suggests the negative effects of social determinants are related to America's system of paying for medical care. The announcement of the availability of an on-line archive of the official first journal of family medicine gives us the chance to acclaim Dr. Geyman, who started the Journal of Family Practice and was the first editor of this journal. And, as usual, there is more! ( $\mathrm{J}$ Am Board Fam Med 2021;34:459-461.)

\section{Everything COVID, Including Clinician Burnout}

In bellwether Bronx NY in 2020, and in less than 3 months, the Department of Family and Social Medicine at Montefiore (Bronx NY) cared for almost 300 patients hospitalized with Coronavirus disease 2019 (COVID-19; see my added reference). Dr. Flatteau and coauthors ${ }^{1}$ chronicle their amazing feat, including changes in inpatient and outpatient care, while also caring for the well-being of their health care workers. Their simultaneously stunning, heartwarming, and sorrowful narrative demonstrate how our discipline has risen to overcome this ongoing challenge.

In addition, for the bulk of family physicians who needed quick and immediate education on caring for the multiple aspects of COVID-19 illness, Leggott et $\mathrm{al}^{2}$ describe Colorado's quick set-up of a community-connected "Just-in-Time" ECHO (Extension for Community Health Outcomes) program to enhance COVID-19 care. This program focused on training, connecting, and supporting primary care practices in the state - another inspiring feat in a time of a pandemic.

COVID-19 continues to significantly impact medical offices. Filippi et al, with the American Academy of Family Physician's Research Network, ${ }^{3}$ report the main concerns by week for family

Conflict of interest: The authors are editors of the $7 A B F M$. physician practices early in the pandemic. COVID19 itself is not the only concern for practices; other concerns include lack of availability and uptake of COVID-19 vaccines. Before vaccines were available in the United States, Parente et $\mathrm{al}^{4}$ surveyed employees and trainees in a health system about willingness to take COVID-19 vaccines. About 4 in 10 intended to delay or avoid the vaccines. Reasons are reported by level of education, race, and other factors. Of note, those who identified as 'black' were less than 1 in 5 as likely as the group to accept this vaccine.

Careful, COVID-19 is not the only serious illness during this pandemic. ${ }^{5}$ COVID-19 illness certainly also reminds us of issues with cardiac defibrillators at the end-of-life. ${ }^{6}$

COVID-19 illness takes its toll on both patients and caregivers. O'Dwyer et $\mathrm{al}^{7}$ found that the COVID-19 epidemic takes a similar toll - particularly emotionally -for those patients with either serious COVID or serious non-COVID-19 illness. Kansas family physicians who cared for COVID-19 patients reported more burnout than those who did not, ${ }^{8}$ a rate that was also slightly higher than reported pre-pandemic. One could guess that loneliness might increase during COVID-19 times, and loneliness is associated with higher levels of burnout, as found in a large pre-pandemic survey of family physicians. ${ }^{9}$ Further, is burnout associated with poor care? ${ }^{10}$ Haag et $\mathrm{a}^{11}$ found that family physicians working collaboratively with pharmacists 
reported less emotional exhaustion which could be a helpful hint, during pandemic times or not.

\section{"Costs" of Providing Patient-Centered Care in the United States}

Spending money on medication for chronic illness rather than covering the costs of basic needs sounds like a recipe for a circular disaster. Meeting fewer basic needs must translate into worse health that may then mean the need for more medicine. Rohatgi et $\mathrm{al}^{12}$ provide data to support this circular spiral into worsened health. This exemplifies the negative results of the American style of paying for medical care.

The American model for Medicaid is also sadly disproportionately influential on access to medical care. Medicaid patients face longer times to first appointment for routine or urgent needs than those with other insurance. ${ }^{13}$ Some types of organizations were more likely to have longer wait times to appointment than others.

Once again, it is shown that providing more resources to assist patients (in this case, patients with diabetes) can show impressive improvements. ${ }^{14}$ The authors provide a helpful description for their full program so others could replicate it. Yet, in the US health system funding is inadequate to provide all the resources necessary for the wide replication of this program. Key quote from Berdahl et $\mathrm{al}^{15}$ "Program administrators for quality measurement and pay-for-performance programs should explore new ways to reward primary care physicians (PCPs) for providing outstanding patient-centered care." We agree! The full article provides more context to support efforts to improve your institution's program.

Our learners similarly experience these costs. The debt of family medicine residents has sadly continued to grow greater than inflation. ${ }^{16}$

\section{Potpourri}

Radon exposure is a clear risk for cancer. ${ }^{17}$ In 1 high-risk area, Schwartz et al asked physicians about their routine for asking about radon, and whether they personally have radon detectors. Many people remain at risk, particularly those with fewer resources. The cost of detection is low, the cost of mediation is high.
In a study of action plan quality for diabetes care, Kjaer et $\mathrm{al}^{18}$ found the quality was moderately high, but less adequate action planning was developed for those of lower literacy or higher social risk. Some plans lacked the level of specificity that would help ensure the likelihood of plan adherence.

Over 9 years and data from 12,000 initial visits for chronic musculoskeletal pain, very few patients were screened for depression. ${ }^{19}$ Family physicians saw the most patients and ordered less testing overall than other specialties. Nonwhite race and Medicaid insurance were associated with more depression screening - in this case, that means better care, which may be unexpected. More specific data are found in the article. Overall, our summary: too little depression screening, too many other tests.

Quitting can be so difficult to do. Quitting tobacco, alcohol, drugs, and.... even health screening that is as easy as writing an order and getting blood drawn! Prostate-specific antigen (PSA) tests are 1 of the tests that are quite overordered for some patients, underordered by others, and often continued for older patients where its usefulness is limited. Overall, PSA testing is overordered for men over age $70 .^{20}$ This report from the Centers for Disease Control and Prevention identifies specific geographic areas that continue with the most excessive rates of ordering, seems like PSA testing is also contagious.

\section{The NEW ONLINE Archives of the Journal of Family Practice and Dr. Geyman as Twice over Founding Editor}

The history of building the literature and research base of the practice of family medicine is not only chronicled, it has now become AVAILABLE! Many thanks go to Dr. Green and coauthors ${ }^{21}$ for their finalization of a long-term goal - the online electronic availability of the articles in the original academic family medicine journal in the United States, the Fournal of Family Practice (FFP). Gratitude must also go to the American Board of Family Medicine Foundation for their support of the effort. This effort for academic journals is reinforced by the article of Phillips et $\mathrm{al}^{22}$ who found that 9 in 10 family medicine clinicians reported accessing family medicine journals for general health care research and 4 in 10 did so weekly.

We have all been the recipient of the amazing work done by the modest Dr. Geyman, the founding 
editor of both $7 F P$ and later the fournal of the American Board Family Practice, later renamed the Fournal of the American Board of Family Medicine. We are pleased that he agreed to write some personal reflections on the FFP's beginning and its role in the development of family medicine. ${ }^{23}$ His story of starting as a general practitioner in rural practice to a developer of 1 of the first family medicine residencies, to later becoming a flying commuter (yes, piloting his personal airplane) to continue his editing with this journal inspires the editors and editorial board and the family medicine community. Thank you.

\section{To see this article online, please go to: http://jabfm.org/content/ 34/3/459.full.}

\section{References}

1. Flattau A, Cristallo J, Duggan M, Gbur M, Fabienne Daguilh M-L, Selwyn P. Clinical redeployment of an academic family medicine department in an early, severe COVID-19 pandemic in the Bronx, NY. J Am Board Fam Med 2021;34:466-473.

2. Leggott K, Willis-Basche L, Saseen JJ, et al. A justin-time implementation of an Extension for Community Health Outcomes (ECHO) program for support of primary care during the COVID-19 pandemic. J Am Board Fam Med 2021;34:481-488.

3. Filippi MK, Callen E, Wade A, et al. COVID-19's financial impact on primary care clinicians and practices. J Am Board Fam Med 2021;34:489-497.

4. Parente DJ, Ojo A, Gurley T, et al. Acceptance of COVID-19 vaccination among health system personnel. J Am Board Fam Med 2021;34:498-508.

5. Titus SJ, Suter RN, Hoang AT, Figel PA. Expanding the differential during the COVID-19 pandemic: fatal West Nile virus neuroinvasive disease. J Am Board Fam Med 2021;34:661-662.

6. Myers SE, Eastwood GL. Implantable cardiac defibrillator deactivation during end of life care in the COVID-19 pandemic. J Am Board Fam Med 2021;34:474-476.

7. O'Dwyer MC, Meixner K, Albiac LC, et al. Health related quality of life for people with acute and chronic illnesses during the COVID-19 pandemic. J Am Board Fam Med 2021;34:509-521.

8. Ofei-Dodoo S, Loo-Gross C, Kellerman R. Burnout, depression, anxiety, and stress among family physicians in Kansas responding to the COVID-19 pandemic. J Am Board Fam Med 2021;34:522-530.

9. Ofei-Dodoo S, Mullen R, Pasternak A, et al. Loneliness, burnout and other types of emotional distress among family medicine physicians: results from a national survey. J Am Board Fam Med 2021;34:531-541.

10. Willard-Grace R, Knox M, Huang B, Hammer H, Kivlahan C, Grumbach K. Primary care clinician burnout and engagement association with clinical quality and patient experience. J Am Board Fam Med 2021;34:542-552.

11. Haag JD, Yost KJ, Kosloski TK, et al. Effect of an integrated clinical pharmacist on the drivers of provider burnout in the primary care setting. J Am Board Fam Med 2021;34:553-560.

12. Rohatgi $\mathrm{KW}$, Humble $\mathrm{S}, \mathrm{McQueen} \mathrm{A}$, et al. Medication adherence and characteristics of patients who spend less on basic needs to afford medications. J Am Board Fam Med 2021;34:561-570.

13. Gotlieb EG, Rhodes KV, Candon MK. Disparities in primary care wait times in medicaid versus commercial insurance. J Am Board Fam Med 2021;34:571-578.

14. Phillips S, Culpepper J, Welch M, et al. A multidisciplinary diabetes clinic improves clinical and behavioral outcomes in a primary care setting. J Am Board Fam Med 2021;34:579-589.

15. Berdahl CT, Easterlin MC, Ryan G, Needleman J, Nuckols TK. Primary care physicians' conceptualization of quality in Medicare's merit-based incentive payment system. J Am Board Fam Med 2021;34:590-601.

16. Phillips JP, Morgan ZJ, Bazemore AW, Peterson LE. Debt of family medicine residents continues to grow. J Am Board Fam Med 2021;34:663-664.

17. Schmitz D, Klug MG, Schwartz GG. Radon knowledge and practices among family physicians in a high radon state. J Am Board Fam Med 2021;34:602-607.

18. Kjaer PH, Fisher L, Potter MB, et al. Examining variations in action plan quality among adults with type 2 diabetes in primary care. J Am Board Fam Med 2021;34:608-617.

19. Carlesso LC, Ehrmann Feldman D, Nahin RL. Specialty differences in initial evaluation of patients with non-acute musculoskeletal pain. J Am Board Fam Med 2021;34:618-633.

20. Berkowitz Z, Zhang X, Richards TB, Sabatino SA, Peipins LA, Smith JL. Multilevel small area estimation of prostate-specific antigen screening test in the United States by age group: 2018 Behavioral Risk Factor Surveillance System. J Am Board Fam Med 2021;34:634-647.

21. Green LA, Puffer JC. Retrieving family medicine's lost literature: The fournal of Family Practice 1974-1999 archive. J Am Board Fam Med 2021;34:477-480.

22. Phillips WR, Sturgiss E, Yang A, et al. Clinician use of primary care research reports. J Am Board Fam Med 2021;34:648-660.

23. Geyman JP. Start of The fournal of Family Practice. J Am Board Fam Med 2021;34:668-669. 